\title{
THE STUDY OF THE BEHAVIOUR OF CARBON EPOXY
}

\section{COMPOSITES USING ACOUSTIC EMISSION}

\section{ARUN NEMA, M. SATHISH KUMAR, SALEEM. M \& BOOPATHY. G}

Vel Tech Rangarajan Dr. Sagunthala R\&D Institute of Science and Technology, Avadi, Chennai, Tamil Nadu, India

\section{ABSTRACT}

Acoustic Emission (AE) is a naturally occurring phenomenon whereby external stimuli, such as mechanical loading, generate sources of elastic waves. AE occurs when a small surface displacement of a material is produced. These $A E$ are generated by localized sources within the structure, which travel through the interior of the material by the shortest path and get picked up by several AE sensors placed on its surface. The Acoustic Emission NDT technique is based on the detection and conversion of these high frequency elastic waves to electrical signals. These are accomplished by directly coupling piezoelectric transducers on the surface of the structure by means of a fluid coolant and are secured with tape, adhesive bonds or magnetic hold downs. The output of each piezoelectric sensor is amplified through a low noise preamplifier, filtered to remove any extraneous noise and furthered processed by suitable electronic equipment. This project aims at studying the behavior of carbon epoxy composite materials, under loaded condition that tend to fail mainly by the following modes, namely, matrix cracking, de-lamination, fiber breakage. The specimens are tested using the acoustic emission technique and sufficient amount of data is acquired from the acoustic emission equipment. Data acquired is processed using MATLAB and various plots are then plotted. The plots between various acoustic emission parameters obtained during the experiments were analysed to understand the process of failure in carbonepoxy composite plate under tensile loading. Further the technique is applied for other specimens and data acquired is analysed to come to a strong conclusion about the behaviour of composites using the acoustic emission technique which proves to be a powerful NDT method

KEYWORDS: Acoustic Emission, NDT, Sensors, Composites \& Flexural Test

Received: Jul 04, 2018; Accepted: Sep 24, 2018; Published: Nov 23, 2018; Paper Id.: IJMPERDDEC201857

\section{INTRODUCTION}

Detection and analysis of AE signals can supply valuable information regarding the origin and importance of a discontinuity in a material. Because of the versatility of Acoustic Emission Testing (AET), it has many industrial applications (e.g. assessing structural integrity, detecting flaws, testing for leaks, or monitoring weld quality) and is used extensively as a research tool. Here the acoustic emission testing is done on composite material specimens' carbon-epoxy type to understand their behaviour when subjected to tensile loads. The data acquired during the specimens are analysed and various results are obtained that provide valuable information

\section{Acoustic Emission}

Acoustic Emission refers to the generation of transient elastic waves during the rapid release of energy from localized sources within a material when it is stressed. AE occurs due to external stimuli, such as mechanical loading. When there is a rapid release of energy in a material, or on its surface. Transient elastic waves are 
generated that produce sound and ultrasound

\section{Acoustic Emission Testing}

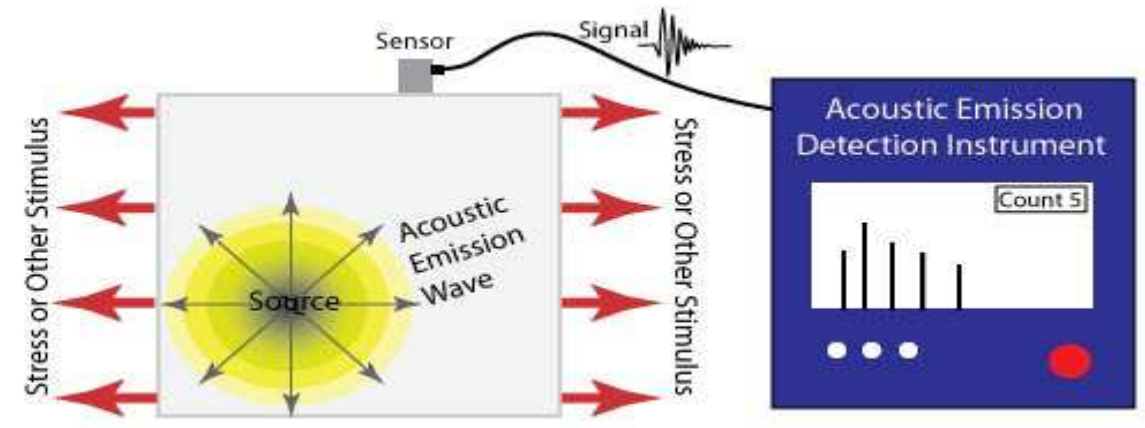

Figure 1: AE-Sensor

The Acoustic Emission NDT technique is based on the detection and conversion of the high frequency elastic waves to electrical signals. This is accomplished by directly coupling piezoelectric transducers on the surface of the structure under test and loading the structure. Sensors are coupled to the structure by means of a fluid coolant and are secured with tape, adhesive bonds or magnetic hold downs. The output of each piezoelectric sensor (during structure loading) is amplified through a low-noise preamplifier, filtered to remove any extraneous noise and furthered processed by suitable electronic equipment.

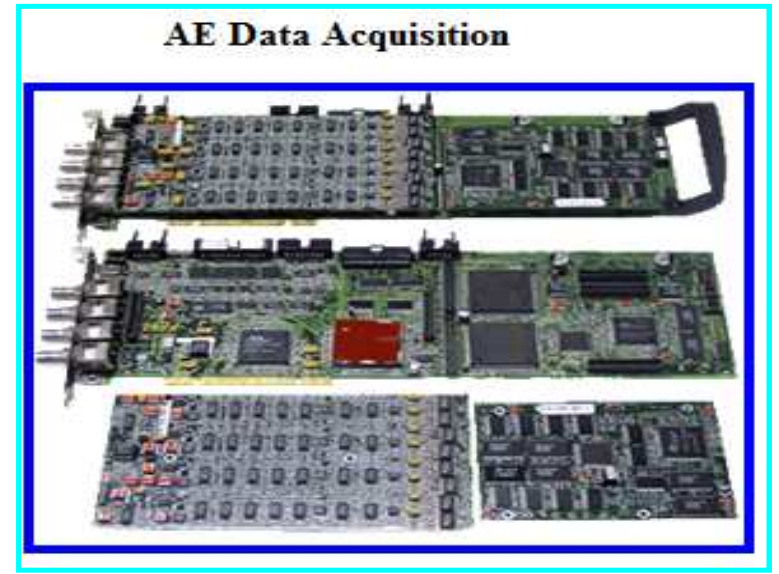

Figure 2: AE Device

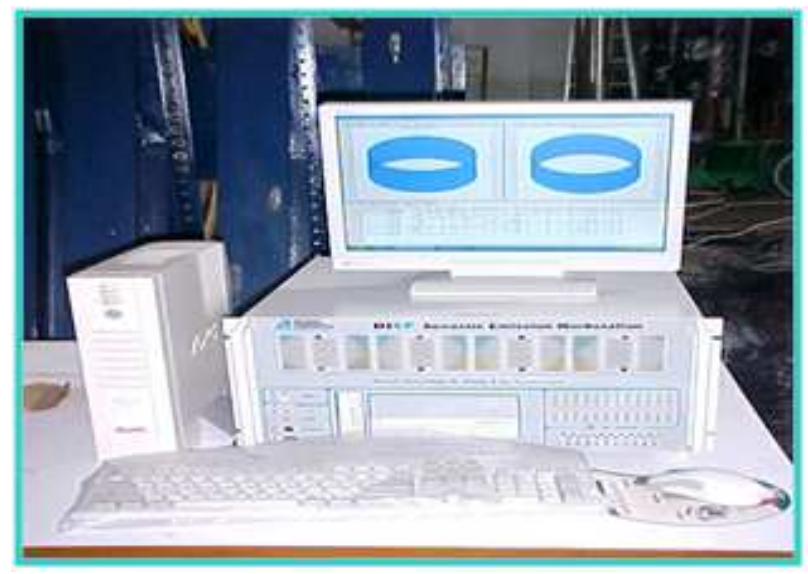

Figure 3: AE-Win

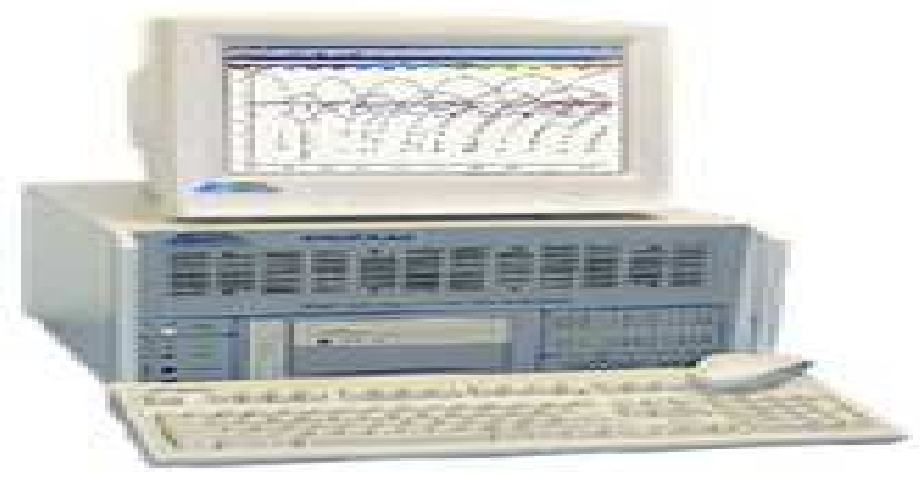

Figure 4: Acoustic Emission Testing Workstation 


\section{AE Sensors}

Purpose of AE sensors is to detect stress waves motion that cause a local dynamic material displacement and convert this displacement to an electrical signal. AE sensors are typically piezoelectric sensors with elements made of special ceramic elements like lead zirconatetitanate

\section{Source Location Using Acoustic Emission}

Linear location is often used to evaluate struts on truss bridges. To calculate the distance of the source location, the arrival time is multiplied by the wave velocity.

Source Location Using 3 sensors

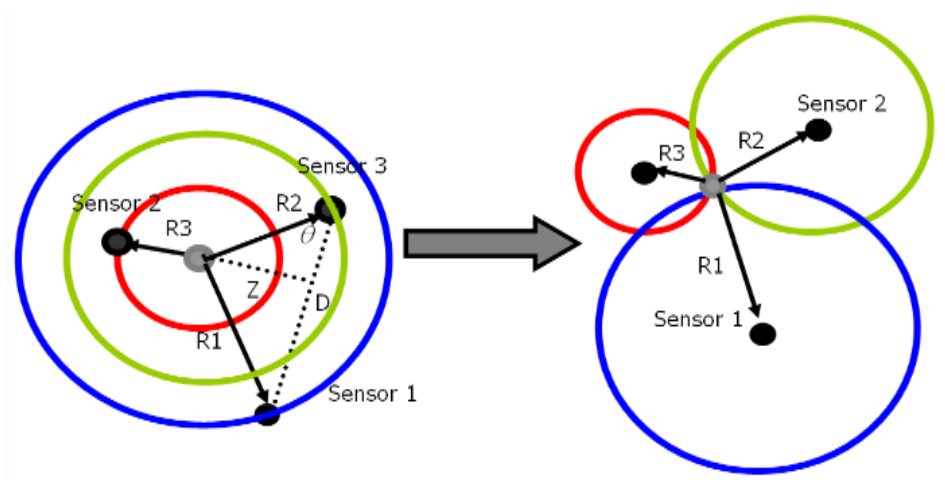

Figure 5: Two Dimensional Source Location

Three sensors are used to locate a source to a point by intersecting two hyperbolae using the same technique as two sensors

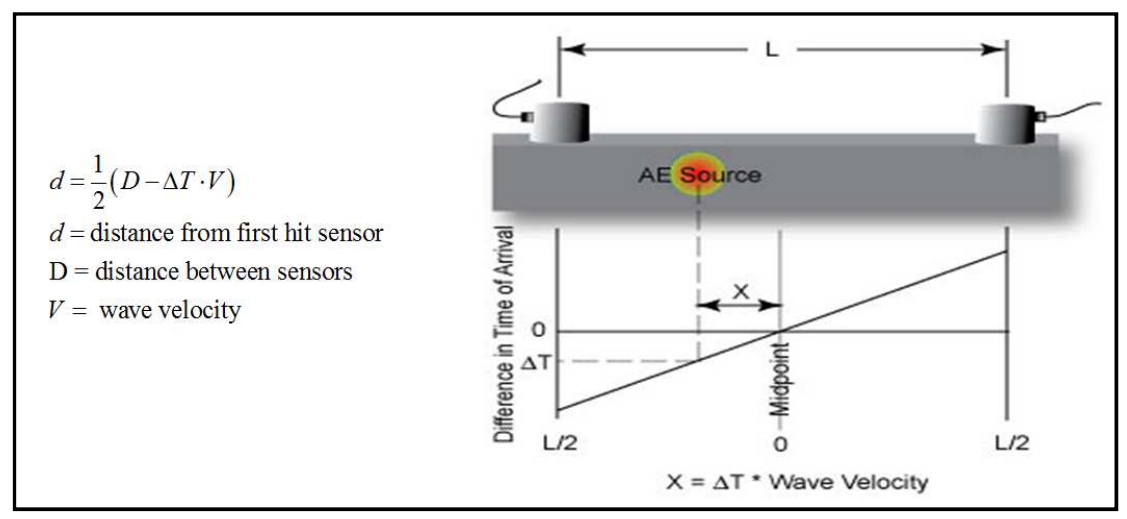

Figure 6: Linear Location Technique

\section{EXPERIMENTAL SETUP}

The experimental setup comprises of a universal testing machine which holds the specimen. A tensile test is carried out using this machine. Sensors are placed on the test specimen, which are connected to the acoustic emission machine through probes. The AE machine acquires the data. 


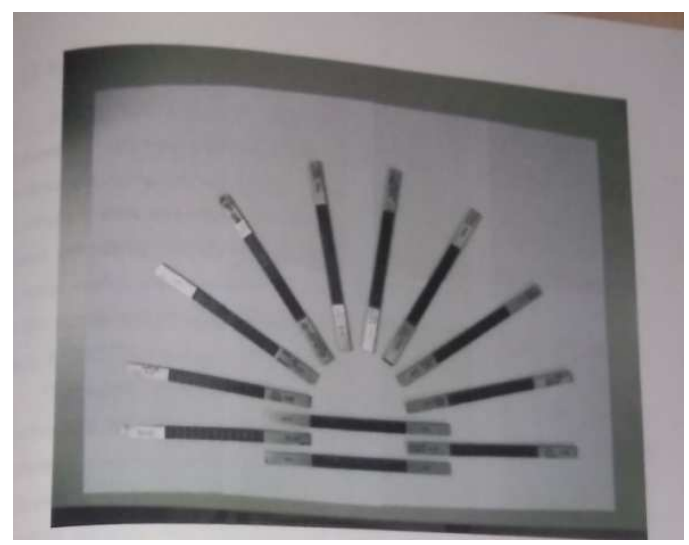

Figure 7: 45 deg. Carbon Epoxy Specimen

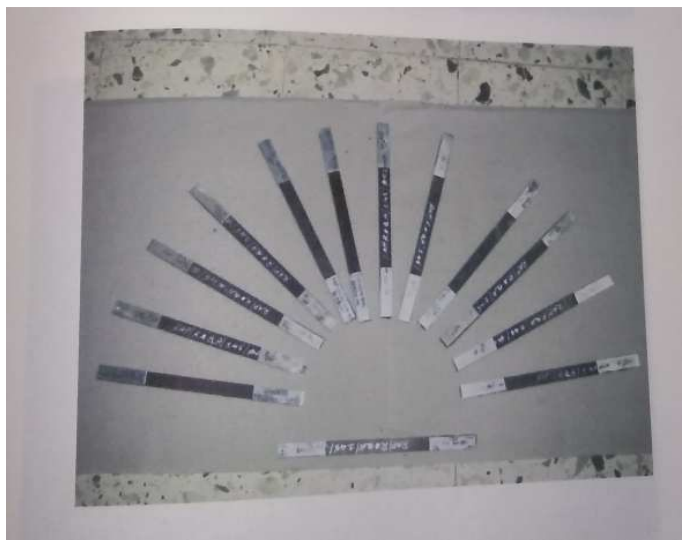

Figure 8: Unidirectional Carbon Epoxy Specimen

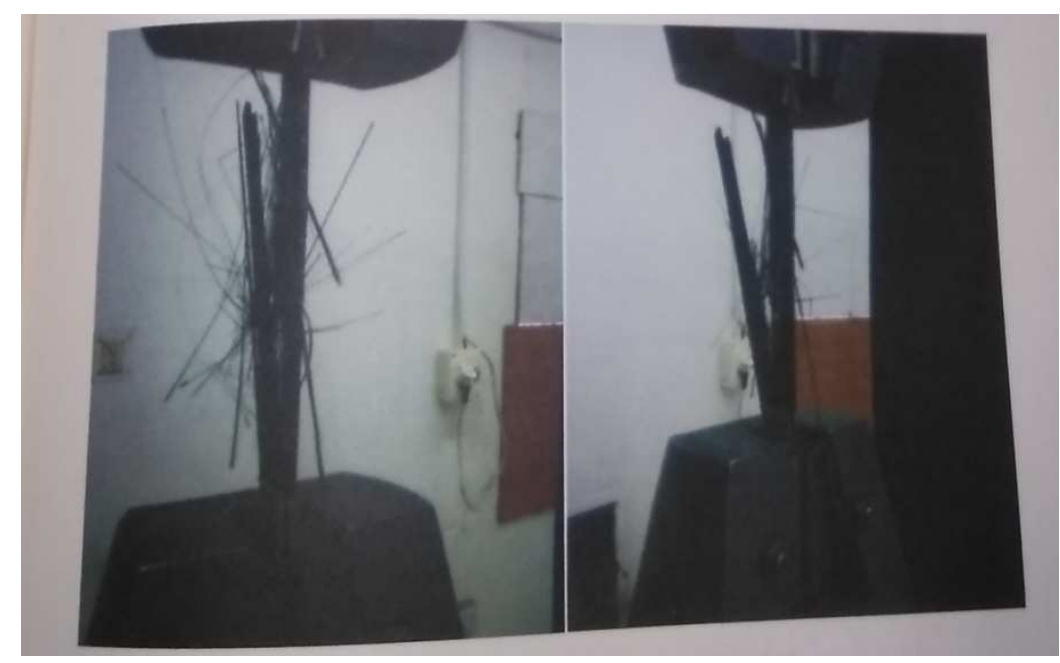

Figure 9: Failed Specimens

\section{RESULTS AND DISCUSSIONS}

\begin{tabular}{|c|c|c|c|c|c|c|c|c|}
\hline \multirow[t]{2}{*}{ Specimen } & \multicolumn{2}{|c|}{ Load(KN) } & \multicolumn{2}{|c|}{ No. of hits test } & \multicolumn{2}{|c|}{$\begin{array}{l}\text { No. of hits } \\
\text { retest }\end{array}$} & \multirow[t]{2}{*}{$\begin{array}{l}\text { Maximum } \\
\text { energy }\end{array}$} & \multirow{2}{*}{$\begin{array}{c}\text { Minimum } \\
\text { energy }\end{array}$} \\
\hline & Test & Retest & Ch. 1 & Ch. 2 & Ch. 1 & Ch. 2 & & \\
\hline $45 \_02$ & 35.74 & & 494 & 409 & & & 4303 & 106 \\
\hline $45 \_03$ & 42.45 & & 557 & 500 & & & 2442 & 75 \\
\hline $45 \_04$ & 37.82 & & 399 & 741 & & & 4232 & 53 \\
\hline $45 \_05$ & 29.73 & & 808 & 771 & & & 4605 & 36 \\
\hline $45 \_10$ & 37.63 & & 366 & 351 & & & 3814 & 67 \\
\hline $45 \_12$ & 25 & 40.58 & 176 & 51 & 393 & 322 & 5469 & 45 \\
\hline $45 \_14$ & 22.71 & & 807 & 469 & & & 7187 & 46 \\
\hline UD_04 & 42 & & 1726 & 1833 & & & 4060 & 25 \\
\hline UD_06 & 54 & 58.23 & 8556 & 9959 & 10 & 197 & 41440 & 17 \\
\hline UD_07 & 39.77 & & 4207 & 5741 & & & 62125 & 610 \\
\hline UD_08 & 41.79 & & 4396 & 3893 & & & 30175 & 827 \\
\hline UD_10 & 54 & 50.48 & 9776 & 11698 & 4 & 16 & 43565 & 23 \\
\hline UD_11 & 59.59 & & 3850 & 2160 & & & 65535 & 813 \\
\hline UD_26 & 69.6 & & 7974 & 7331 & & & 27233 & 692 \\
\hline
\end{tabular}

Figure 10: Specimen Characteristics Compilation 


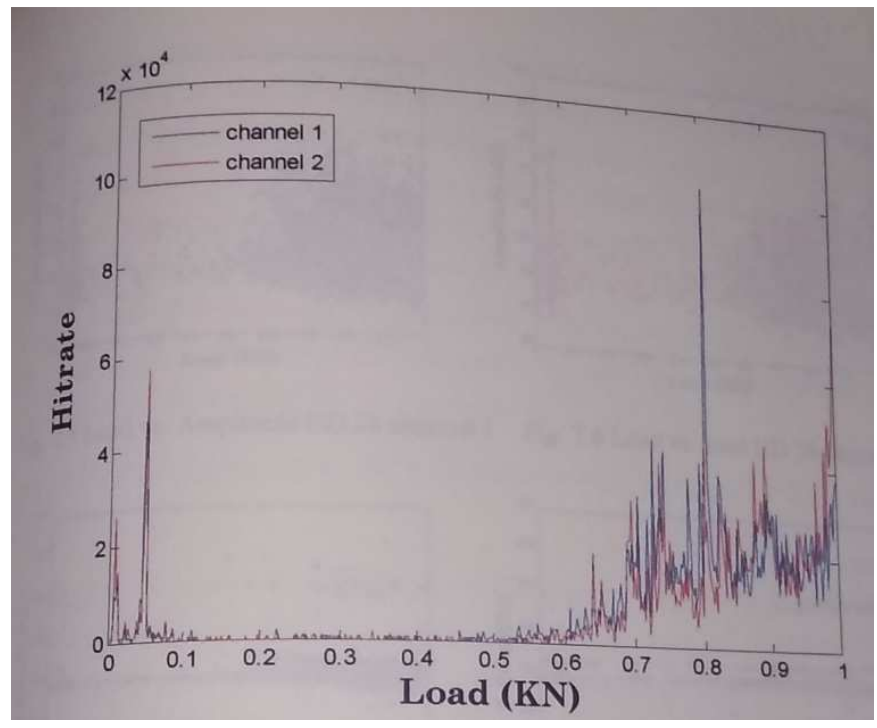

Figure 11: Load vs Hit Rate

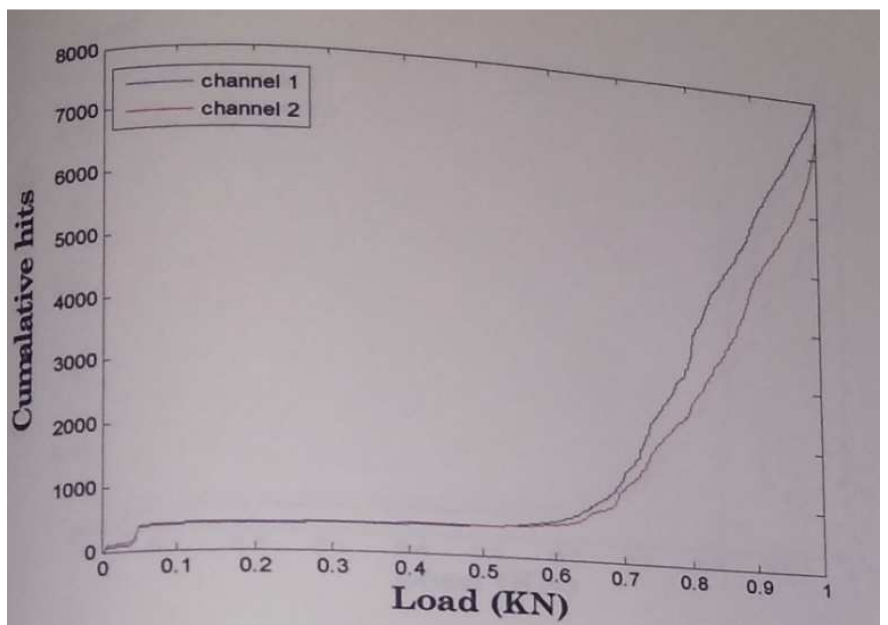

Figure 12: Load vs Cumulative Hits

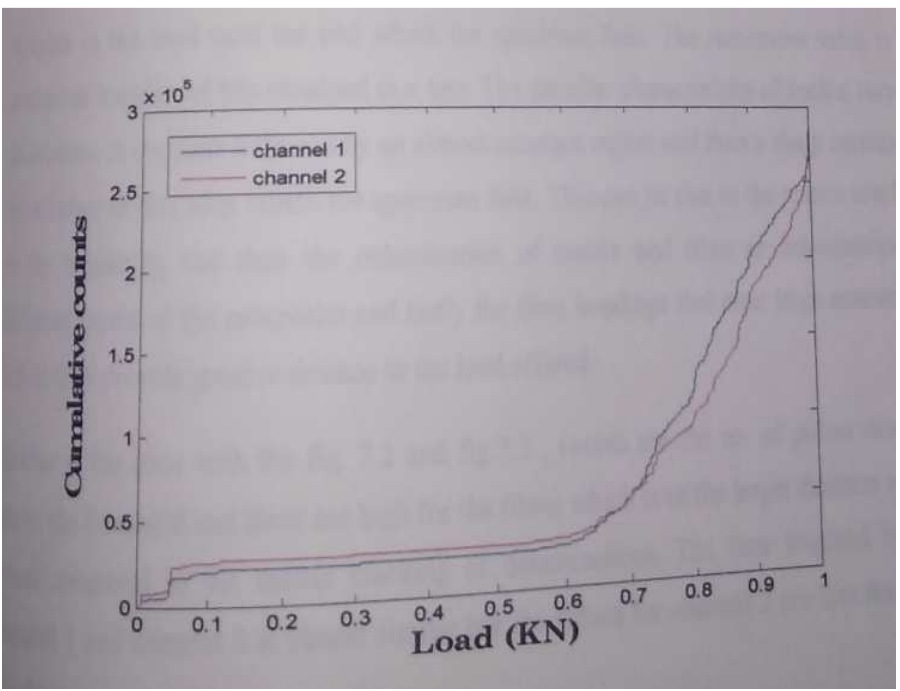

Figure 13: Load vs Cumulative Hits 


\section{Data Analysis}

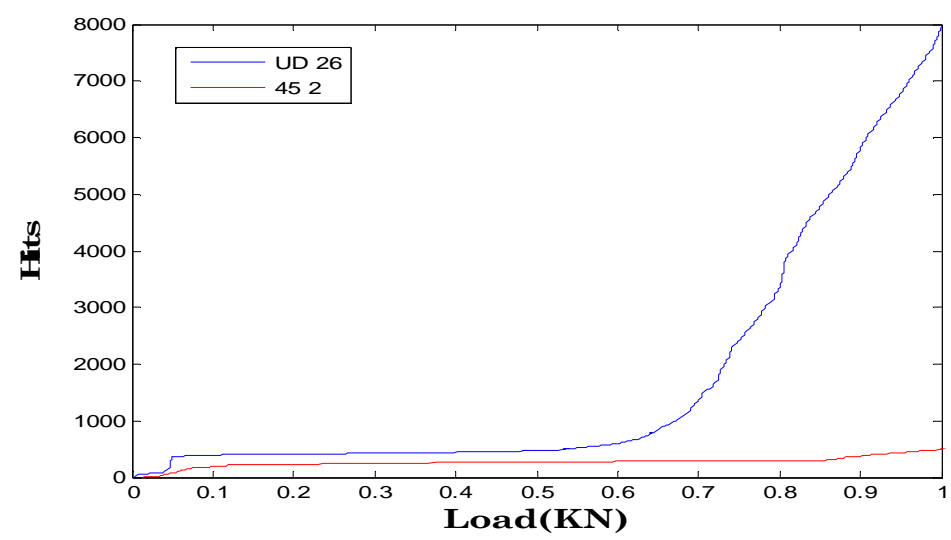

Figure 14: Load vs Hits

The above figure shows the comparison between the hits vs load for UD 26 and 45-2 specimens. The hits acquired in the ud specimen are far greater than the 45-2 specimen.

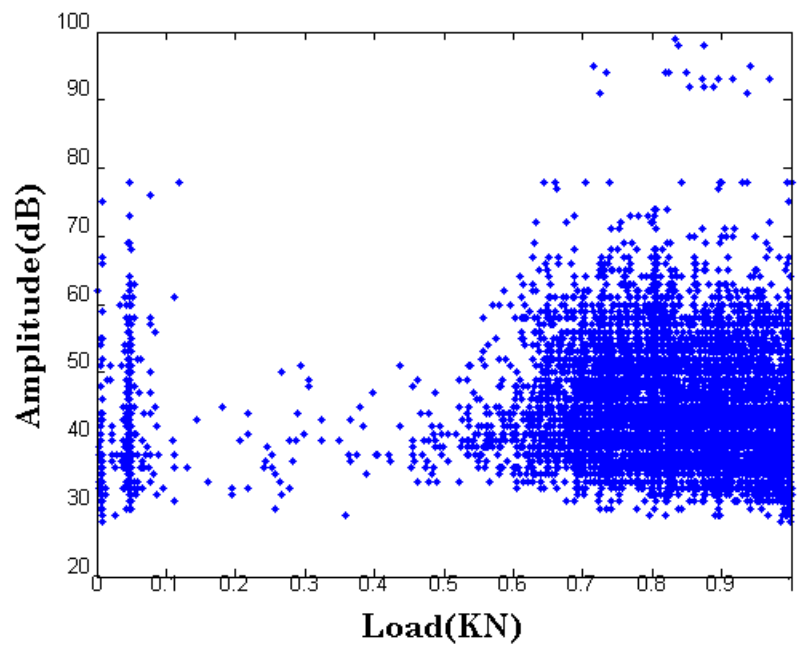

Figure 15: Load vs Amp

The amplitude increases, then decrease and then increases to a very large value where the specimen breaks. The amplitude rise in the first segment signifies matrix cracking and then a significant zone of silence showing delaminations and when the fibre breakage with a very high amplitude. 


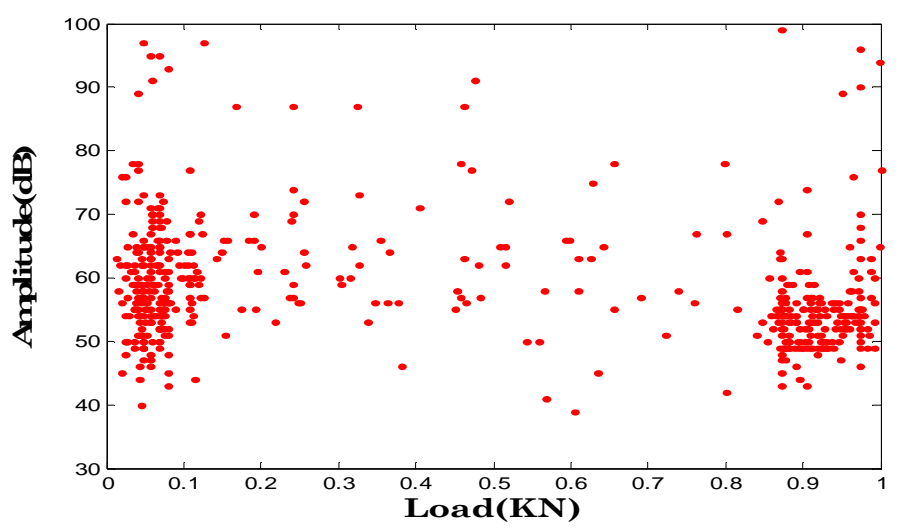

Figure 16: Load vs Amp

The left figure is for ud and the right for 45 degree specimen.

The plot is scattered all over showing weak nature of the specimen. Whereas, matrix cracking and fibre breakage zones are clearly seen.

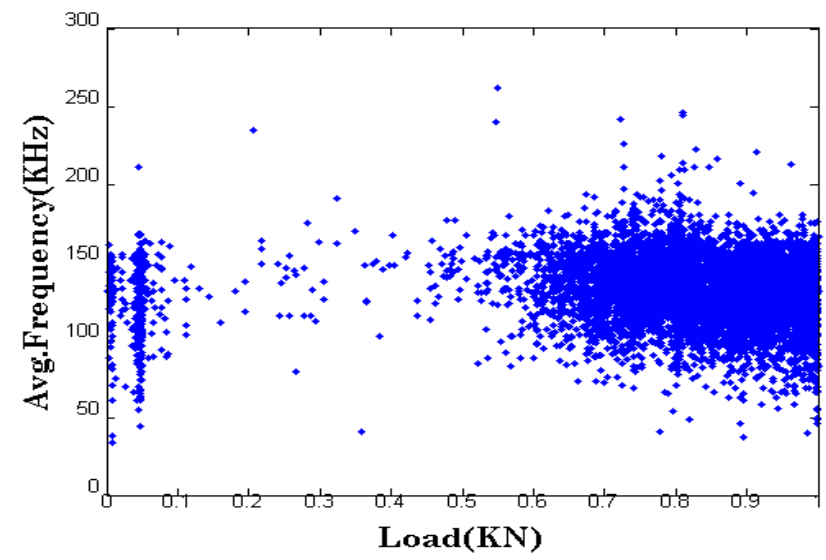

Figure 17: Load vs Frequency

Frequency vs load plot for udspecimen. The plots are similar to the amplitude graphs.

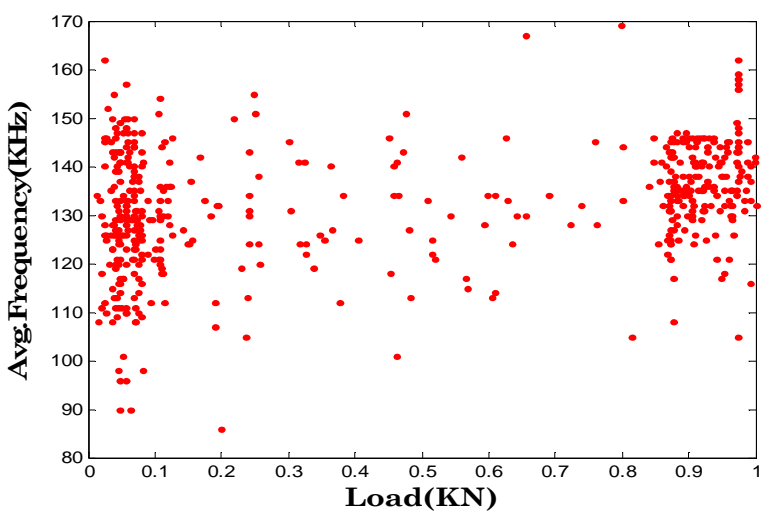

Figure 18: Load vs Frequency

Frequency vs load plot for 45 degree specimen 


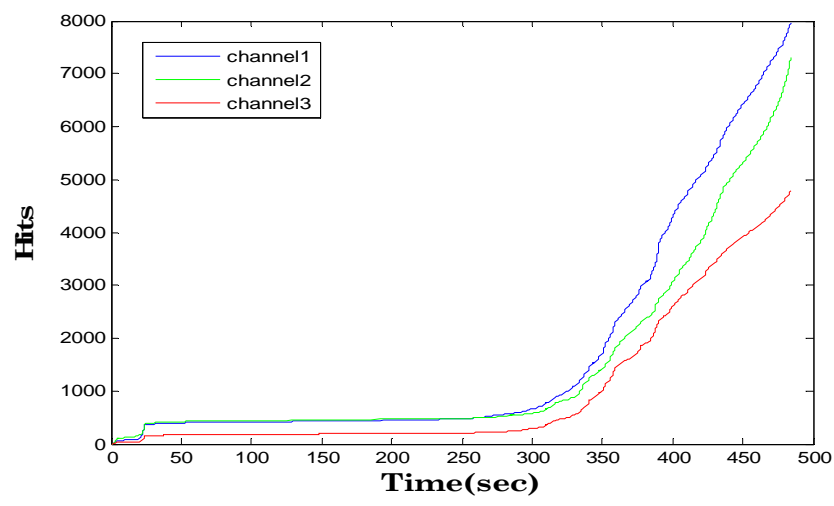

Figure 19: Time vs Frequency

The figure shows the plot between hits and time for anud specimen. Channels are the different sensors that detect the emissions. The plots are similar showing that any channel detects almost the same data, which can be utilized for analysis.

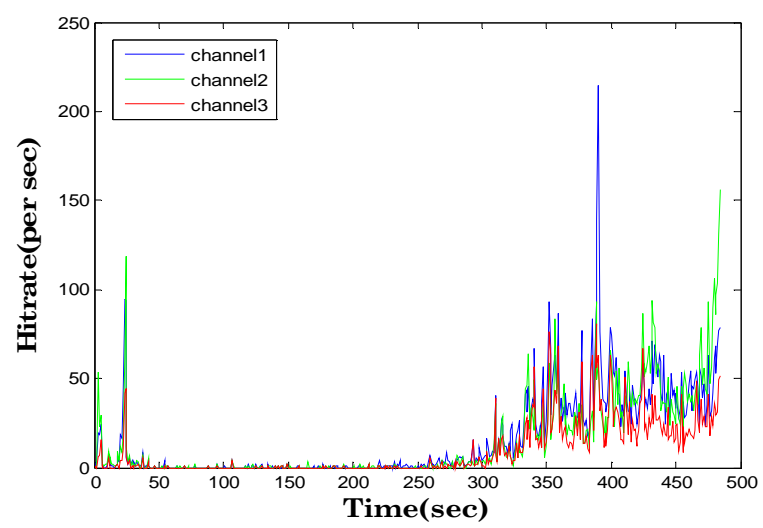

Figure 20: Time vs Frequency

The hit rate is the no. of hits detected per second. The maximum no. of hits are observed for channel 1 at time 400 sec.

This also shows that more no of hits are obtained at matrix cracking stage and even more at the later part where fibres tend to break.

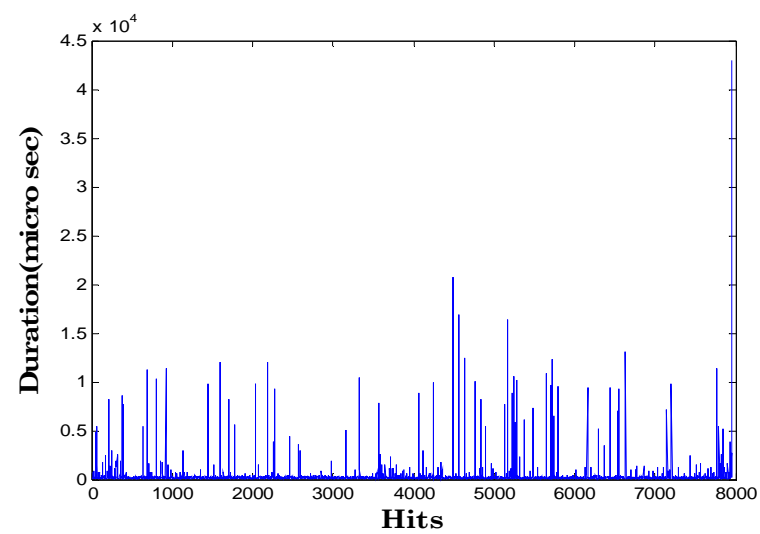

Figure 21: Duration vs Hits 


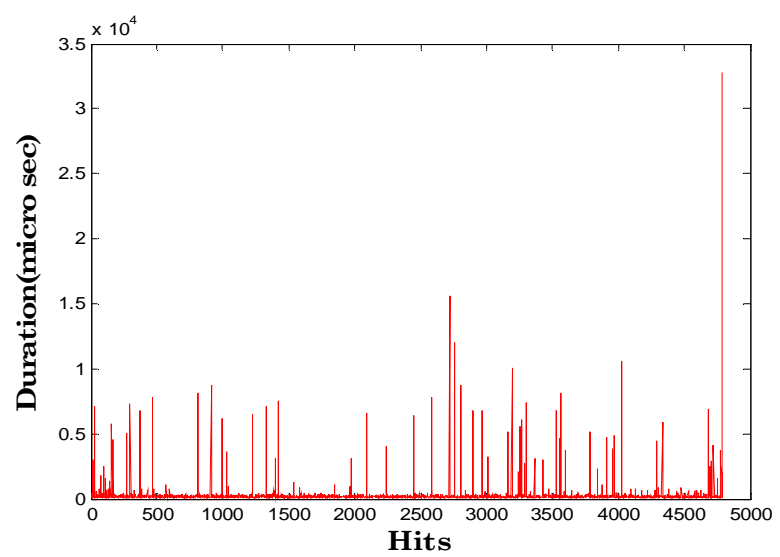

Figure 22: Duration vs Hits

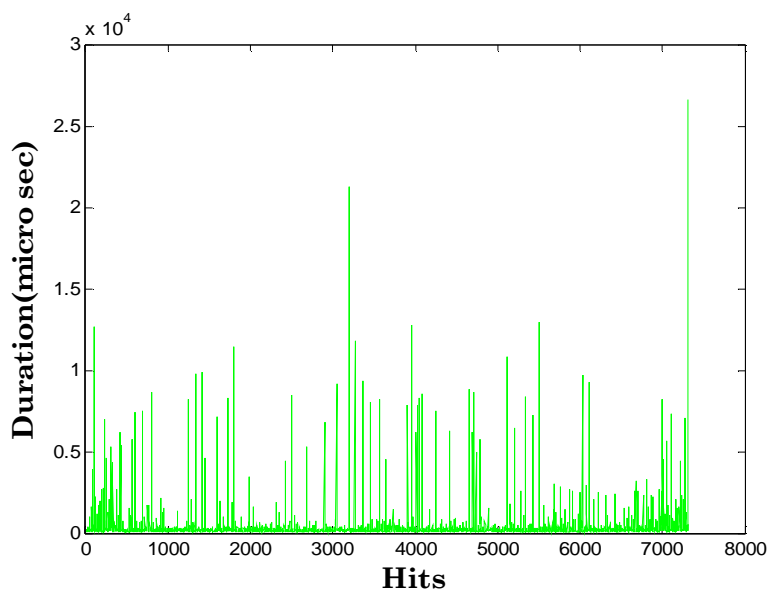

Figure 23: Duration vs Hits

From the figures it is observed that for all the channels 1, 2 and 3 the duration is higher at the end. Signifying stretching of the fibers relatively producing the larger duration waves.

\section{CLASSIFICATION OF ACOUSTIC EMISSIONDATA}

Understanding Graphs using k-Means Method

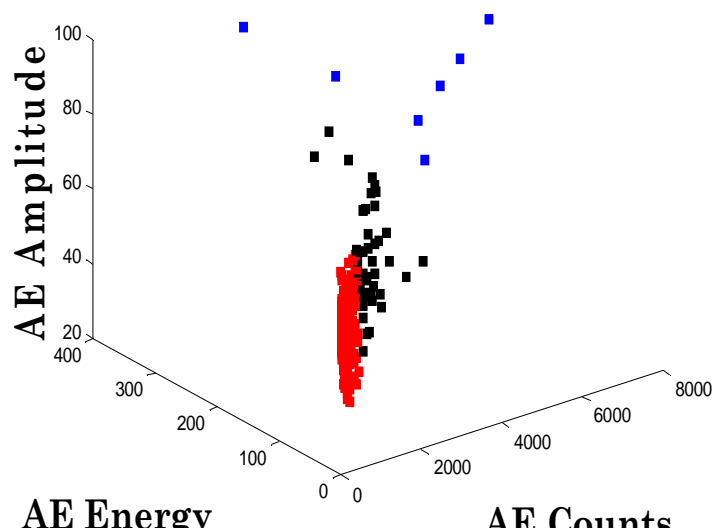

Figure 24: Amplitude vs. Energy vs, Count 45_2_1 


\section{Understanding Graphs using the SOM Clustering, Network}

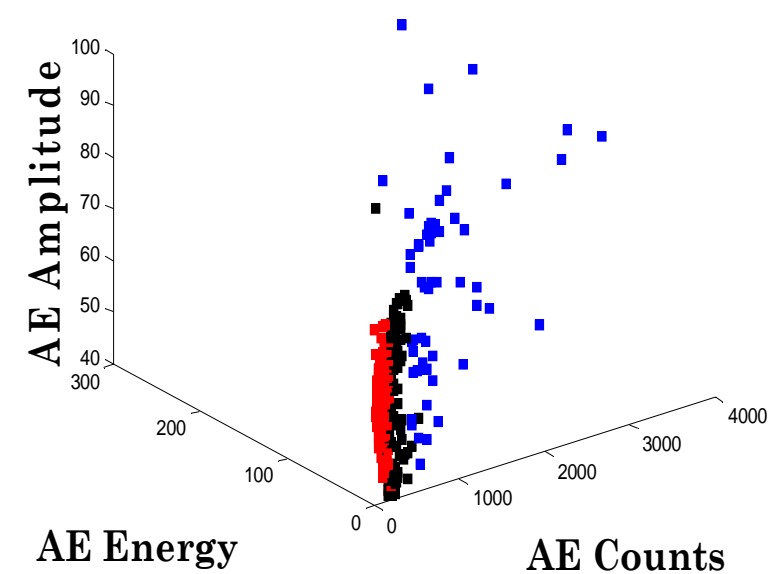

Figure 25: Amplitude vs. Energy vs Count 45_4_1

\section{CONCLUSIONS}

This study produced a number of important results for the understanding of both the analysis of acoustic emission signals from composite damage as matrix microcraking, matrix/matrix friction, fibre / matrix friction and fibre breakage. A no. of experimentswas carried out to successfully correlate the results that helped determine the behaviour of composites. Good amount of hits data was obtained. The frequency plots showed a common trend and a good range of frequency values was obtained. The amplitude and load data were successfully plotted and showed three distinct regions clearly that is matrix cracking, delaminations and the fibre breakage. The hitrate for different specimens was successfully analysed. The cumulative plots also showed a good trend in their behaviour. MATLAB was used extensively to import the data and group it accordingly and procedures were adopted to implement programs that considerably reduce time and effort. It proved to be very useful in analysing data and plotting different graphs. The classification of the acoustic emission data was successfully performed using the k-means method, self-organized maps and the competitive layer neural networks methodology.

\section{REFERENCES}

1. Real-time frequency determination of acoustic emission for different fracture mechanisms in carbon/ epoxy composites Peter J.de Groot Peter A. M. Wijnen Roger B.F. Janssen Composites Science and Technology Volume 55, Issue 4, 1995, Pages 405412

2. In situ sensing of impact damage in epoxy/glass fiber composites using percolating carbon nanotube networks panel Limin Gaoa Tsu-Wei Choub ErikT. Thostensonb Zuoguang Zhanga Magali Coulaud Carbon Volume 49, Issue 10, August 2011, Pages 3382-3385

3. An acoustic-emission characterization of the failure modes in polymer-composite material MGiordanoa ACalabrobC EspositobAD' AmorecL Nicolaisc Composites Science and Technology Volume 58, Issue 12, December 1998, Pages 19231928

4. Evaluation of thermally-aged carbon fiber/epoxy composites using acoustic emission, electrical resistance and thermogram Pyeong-SuShina Jong-HyunKima Ha-Seung Parka Yeong-Min Baeka Dong-Jun KwonaK. Lawrence De Vriesb Joung- Man Parkab Composite Structures Volume 196, 15 July 2018, Pages 21-29 
5. Evaluation of thermally-aged carbon fiber/epoxy composites using acoustic emission, electrical resistance, contact angle and thermogram J. M. Park; P. S. Shin; J. H. Kim; H. S. Park; Y. M. Baek; K. L. De Vries Proceedings Volume 10596, Behavior and Mechanics of Multifunctional Materials and Composites XII; 105961N (2018)

6. Raja, R., \& Jannet, S. Experimental Investigation Of High Speed Drilling Of Glass Fiber Reinforced Plastic (GFRP) Composite Laminates Made Up Of Different Polymer Matrices.

7. Barely visible impact damage assessment in laminated composites using acousticemissil Milad Saeedifara Mehdi Ahmadi Najafabadia Dimitrios Zarouchasb Hossein Hosseini Toudeshkyc Meisam Jalalvandd Composites Part B: Engineering Volume 152, 1 November 2018, Pages 180-192

8. Damage characterization of stiffened glass-epoxy laminates under tensile loading with acoustic emission monitoring $V$. Arumugama K. Saravanakumara C. Santulli Composites Part B: Engineering Volume 147, 15 August 2018, Pages 22-32

9. In situ self-sensing of delamination initiation and growth in multi-directional laminates using carbon nanotube interleaves panel Lulu Shena Ling Liua Wei Wanga Yexin Zhou Composites Science and Technology Volume 167, 20 October 2018, Pages 141-147

10. An experimental study of water diffusion in carbon/epoxy composites under static tensile stress Corentin Humeau ${ }^{a}$ PeterDavies ${ }^{a}$ FrédéricJacquemin Composites Part A: Applied Science and Manufacturing Volume 107, April 2018, Pages 94-104

11. Acoustic emission monitoring of thin ply hybrid composites under repeated quasi-static tensile loading Fotouhi, Mohamad and Suwarta, Putu and Jalalvand, Meisam and Czél, Gergely and Wisnom, Michael R. (2018). FME Transactions, 46 (2). pp. 238244.

12. Acoustic emission for interlaminar toughness testing of CFRP: Evaluation of the crack growth due to burst analysisFabianLissek ${ }^{a}$ AndreasHaeger ${ }^{b}$ VolkerKnoblauch $^{b}$ SergejHloch $^{\text {cd }}$ FrankPude $^{e}$ MichaelKaufeld ${ }^{\text {ae }}$ Composites Part B: Engineering Volume 136, 1 March 2018, Pages 55-62

13. Saleem, M.; Gopi, E.; Rajagurunathan; Vishnu, V.; and Juliyana, S.J. (2017). Design and fabrication of natural ramie/epoxy composite bicycle frame with experimental and FEA-abaqus analysis. International Journal of Mechanical Engineering \& Technology, 8(6), 575-586. 
